\title{
수질샘플빈도에 따른 산림유역의 비점원오염부하특성 \\ Characteristics of Nonpoint Source Pollutant Loads from Forest watershed with Various Water Quality Sampling Frequencies
}

\author{
신민환** - 신용철* - 허성구** - 임경재** · 최중대**, ${ }^{+}$ \\ Shin, Min Hwan** ${ }^{*}$ Shin, Yong Chul* ${ }^{*}$ Heo, Sung Gu** Lim, Kyoung Jae** C Choi, Joong Dae**,
}

\begin{abstract}
A monsoon season monitoring data from June to September, 2005 of a small forested watershed located at the upstream of the North Han River system in Korea was conducted to analyze the flow variations, the NPS pollutant concentrations, and the pollution load characteristics with respect to sampling frequencies. During the 4month period, $1,423 \mathrm{~mm}$ or $79.2 \%$ of annual rainfall $(1,797 \mathrm{~mm})$ were occurred and more than $77 \%$, $54 \%$ and $68 \%$ of annual $\mathrm{T}-\mathrm{N}, \mathrm{NO}_{3}-\mathrm{N}$ and T-P loads discharged. Flow rate was continuously measured with automatic velocity and water level meters and 58 water quality samples were taken and analyzed. It was analyzed that the flow volume by random measurement varied very widely and ranged from $79 \%$ to $218 \%$ of that of continuous measurement. It was recommended that flow measurement of small forested watersheds should be continuously measured with automated flow meters to precisely measure flow rates. Flow-weighted mean concentrations of $\mathrm{T}-\mathrm{N}, \mathrm{NO}_{3}-\mathrm{N}$ and T-P during the period were $2.114 \mathrm{mg} / \mathrm{L}, 0.836 \mathrm{mg} / \mathrm{L}$, and $0.136 \mathrm{mg} / \mathrm{L}$, respectively. T-N, $\mathrm{NO}_{3}-\mathrm{N}$ and T-P loads were sensitive to the number of samples. And it was analyzed that in order to measure the pollution load within the error of $10 \%$ to the true load, the rate of sampling frequency should be higher than $89.7 \%$ of the sample numbers that were required to compute the true pollution load. If it is compared to selected foreign research results, about 10 water samples for each rainfall event were needed to compute the pollution load within $10 \%$ error. It is unlikely in Korea and recommended that thorough NPS pollution monitoring studies are required to develop the standard monitoring procedures for reliable NPS pollution quantification.
\end{abstract}

Keywords : Forest watershed, Pollutant loads, Water quality, Sampling frequencies, Relative errors

\section{I. 서 론}

우리나라는 전국토의 $65 \%$ 이상이 산림으로 이루어 져 있다. 따라서 하천의 대부분이 산지에서 발원하기

* 강원대학교 농업과학연구소

** 강원대학교 농업생명과학대학

† Corresponding author. Tel.: +82-33-250-6464

Fax: +82-33-251-1518

E-mail address: jdchoi@kangwon.ac.kr
때문에 산림은 하천 수량과 수질에 절대적인 영향을 미치고 있다. 특히, 강원도에 위치한 북한강의 경우 수도권 일대의 용수공급을 위한 주요 상수원이기 때 문에 자연환경이 잘 보전되어 있다. 그러나 우리나라 에서 인구밀도가 가장 낮고 산업시설이 거의 없는 청 정지역이라고 불리는 소양강 상류유역에서도 하천수 의 총인과 총질소 농도가 매우 높게 발생하고 있다 (신 등, 2006; 최중대, 1996). 환경부에서는 하천 및 
호소의 수질개선을 위한 비점원오염 저감대책방안을 수립하였으나 성과가 미비한 실정이다(환경부, 2005). 비점원오염은 점원오염과 달리 오염물의 종류, 독성, 발생량, 인간 및 동 - 식물에 미치는 영향들을 명확 하게 나타내기가 매우 어렵다. 유역에서 배출되는 비 점원 오염물질은 유역의 식생상태, 지리적 특성, 기 상인자 및 기타 요인에 따라 영향 받는다. 또한 강우 강도, 강우지속시간, 강우수질, 유달거리, 개발지역의 유무 등에 따라 그 영향의 정도가 달라진다(최중대, 1999; 한강수계관리위원회, 2005). 비점원오염은 지 역적 특성이 강하기 때문에 어느 한 지역에서 성공한 규제방법은 인근유역이나 혹은 다른유역에서는 실패 할 수도 있다. 따라서, 유역의 오염물질유출에 영항을 미치는 인자들의 특성을 고려하여 조사 연구가 수행 되어져야 하며, 유역에서 발생하는 오염부하량을 정 확히 산정하여야 한다. 한강수계관리위원회(2005)의 연구에 따르면 급경사지가 많은 북한강 유역의 경우 $\mathrm{T}-\mathrm{N}, \mathrm{NO}_{3}-\mathrm{N}$ 및 $\mathrm{T}-\mathrm{P}$ 의 오염부하는 연평균강우량의 $70 \%$ 이상이 발생하는 6 9월동안 연오염부하의 $82 \%$, $84 \%$ 및 $87 \%$ 이상이 발생한다. 따라서 홍수기인 6 9월의 발생하는 유량 및 수질시료를 정밀하게 측정 및 분석하여 오염부하를 산정하여야 한다. 일반적으 로 유량자료는 비교적 정확하게 측정될 수 있으나, 수질시료의 채취 및 분석은 시간과 비용문제로 인해 제약을 받는다. 따라서 정확한 오염부하의 산정을 위 해서는 연속적인 유량산정 뿐만 아니라 하천수의 농 도특성을 반영할 수 있는 효과적인 샘플링 전략이 필요하다(Clement and Buzas, 1999; Richards and Holloway, 1987; Robertson and Roerish, 1999; Miller et al., 2001). 그러나 우리나라에서는 수질샘 플빈도가 오염부하량에 미치는 영향에 관한 연구가 아직까지 거의 이루어지지 않고 있다. 오염부하산정 오차를 5\% 미만으로 산정하기 위해서는 Yaksich and Verhoff(1983) 는 강우사상별 12 20개 의 수질시 료가 채취되어야 하며, Roman-Mas et al.(1994)은 강우사상별 20 개 이상의 수질시료가 필요한 것으로 보고하였다. 그러나 유역특성 등이 다른 외국의 자료 를 우리나라에 적용하기는 어려울 뿐만 아니라 우리 나라에서 강우사상별 10 개 이상의 수질시료의 채취
및 수질분석은 비용문제 인하여 현실적으로 매우 어 렵다. 따라서, 충분한 크기의 수질시료 분석이 어려울 때는 수질시료의 크기와 오염부하 사이의 관계를 분 석하여 최소의 수질시료로 참값에 가까운 오염부하를 산정할 필요가 있다.

본 연구에서는 산림유역 소하천에서 6 9월 동안 측정된 수량과 수질측정자료를 이용하여 수량과 수질 측정빈도가 산림유역의 비점원오염부하에 미치는 영향 을 분석 하였다. 본 연구결과는 신뢰성 있는 비점원 오염부하를 산정하기 위한 최소의 샘플빈도를 결정하 여 효율적인 유역관리를 위한 정책자료로 활용될 수 있을 것이다.

\section{2. 연구방법}

\section{가. 연구대상 유역}

강원대학교 학술림은 한반도의 중앙부에 위치하고 있으며, 행정구역으로는 강원도 춘천시 동산면과 홍 천군 북방면의 일원에 걸쳐 위치하고 있다. 학술림의 지형은 주봉인 대룡산 $(899 \mathrm{~m})$ 을 정점으로하여 남쪽 으로 응봉 $(753 \mathrm{~m})$, 연엽산 $(850 \mathrm{~m})$, 구절산 $(750 \mathrm{~m})$ 이 이어져 동서로 분수령을 이루고 있으며, 일부 능선과 암석지를 제외하고 임지의 평균경사도는 20 25도 정도이다. 하천은 대룡산에서 발원하여 북방리를 지나 는 북방천, 응봉에서 서쪽으로 흐르는 원창천, 연엽산 에서 발원하여 봉명리를 지나는 봉명천, 구절산에서 남쪽으로 흐르는 성동천이 있는데, 이들은 모두 홍천 강을 거쳐 북한강으로 합류하고 있다. 북한강 중류에

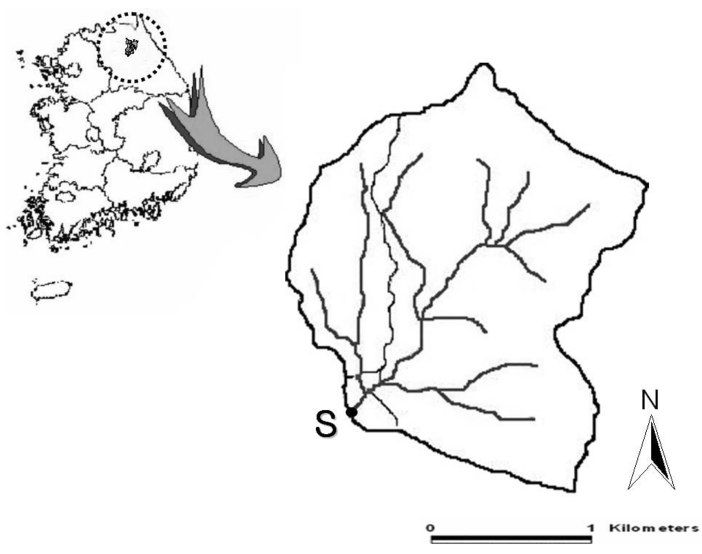

Fig. 1 Schematic sketch of the study watershed 
위치하고 있는 학술림 유역은 산간계곡으로 이루어 진 전형적인 산림지역이다. 학술림 유역에는 임산실습 을 위한 제탄소 등 교육과 연구시설이 설치되어 있다. 학술림 유역의 경계와 관측지점은 Fig. 1 과 같다.

\section{나. 학술림 산림유역의 실측유량 및 수질특성}

우리나라의 경우 강우는 주로 여름철 장마철에 $70 \%$ 정도 집중되어 있다. 따라서 강우와 밀접한 관계가 있 는 농촌과 산림유역의 비점원오염부하의 유출은 여름 철 강우기에 집중되어 있다. 한강수계관리위원회(2005) 의 연구에 따르면 SS, BOD, T-N 및 T-P 등 대표 적인 비점원오염은 6 9월의 여름철 강우기에 연오 염부하량의 각각 $76 \%, 79 \%, 82 \%$ 및 $87 \%$ 가 배출되 는 것으로 보고하였다. 따라서 비점오염부하의 정량 화에 가장 많은 영향을 미치는 시기는 여름철 장마 기이며 이때의 유출량과 수질의 측정 빈도가 비점오 염부하의 산정에 매우 중요하다. 따라서 본 연구에서 는 수량과 수질의 측정빈도가 상대적으로 높았던 2005년 6 9월 사이의 자료를 중심으로 분석하였 다. 유량산정을 위하여 강원대학교 산림유역 소하천의 측정 지점에 압력식 수위계(독일 OTT 사의 Orphimedes)를 설치하였으며 수위측정은 강우시 5 분간격 그리고 비강우시 30 분 간격으로 수행하였다. 평시와 강우시 수위와 유량을 동시에 측정한 자료로 유도한 수위-유량곡선(Rating curve)으로 수위자료를 유량 으로 환산하였다. 울창한 식생으로 피복된 토양의 경 우 강우의 차단(Interception)과 토양 침투율이 크기 때문에 5 $10 \mathrm{~mm}$ 미만의 강우시에는 강우유출수가 거의 발생하지 않는다. 강원도 춘천시에 위치한 학술 림 소하천 유역은 극히 제한된 개발구역을 제외한 $99 \%$ 이상이 식생 및 낙엽등에 피복되어 있기 때문에 유 효강우를 $10 \mathrm{~mm}$ 로 설정하였다. 따라서 본 연구에서는 $10 \mathrm{~mm}$ 이상의 강우시 강우사상별로 1 3개 이상 측정된 채취된 58 개의 수질시료를 분석하였으며, $\mathrm{T}-\mathrm{N}$, $\mathrm{NO}_{3}-\mathrm{N}$ 및 $\mathrm{T}-\mathrm{P}$ 의 분석항목을 환경부 제정 수질공 정시험법의 제반규정에 따라 분석하였다(수질공정시 험법, 1996).

다. 수질시료의 무작위추출(Random sampling)
일반적으로 강우시 강우유출수에 함유된 오염물질 농도는 첨두유출이 발생하기 전에 가장 높게 나타나 며, 첨두유출 이후에는 점점 감소하는 특성을 보인다. 따라서, 비점원오염농도 및 부하특성을 산정하기 위 해서는 단일강우사상별로 첨두유출의 전 - 후로 오염 농도의 변화를 측정할 수 있도록 수질샘플링이 이루 어져야 한다. 본 연구에서 유량은 자동수위계의 설치 를 통해 연속적으로 매우 정밀하게 측정되었다. 수질 분석은 우리나라에서 통상적으로 수행하고 있는 수 질관측보다는 매우 많은 4 개월 동안 58회의 수질샘 플을 채취하고 분석하였다. 특히 수질분석은 강우사상 별로 첨두유출을 전·후로 3 4회 정도 수질시료를 채취하고 분석하였기 때문에 상당히 정밀하게 오염부 하량이 산정되었다고 판단하고 있다. 그러나 다른 많 은 연구에서는 유량측정이 연속적이지 못하여 오염부 하 산정에 매우 중요한 인자인 유량의 정량화가 잘 이루어지지 않을 뿐만 아니라 수질샘플 채취 숫자가 많지 않아 대표적인 농도의 산정이 어렵기 때문에 오 염부하량에 오차가 많을 것으로 판단하고 있다. 따라 서 본 연구에서는 샘플빈도가 오염부하산정에 미치는 영향을 평가하기 위하여 2005년 6월부터 9월까지 강 우시에 측정된 전체 58 개의 수질시료를 무작위로 4 회, 8회, 12회, 16회, 20회, 24회, 28회, 32회, 36 회, 40회, 44회, 48회 및 52회 추출하여 수질샘플빈 도에 따른 오염부하량을 산정하여 실측값에 대한 상 대오차(Relative error)를 분석하였다. 연속적으로 측 정된 유량자료와 수질시료를 공식 (1)을 이용하여 오 염부하를 산정하였으며, 상대오차공식은 공식 (2)와 같다.

오염부하량 $=\frac{\sum_{i=1}^{n} C_{i} Q_{i}}{A}$

여기서, $\mathrm{A}$ 는 총 유역면적, $\mathrm{n}$ 는 채취된 수질시료수, $\mathrm{C}_{\mathrm{i}}$ 는 수질농도, $\mathrm{Q}_{\mathrm{i}}$ 는 연속적으로 측정된 유량자료를 나타낸다.

$\mathrm{R}=\frac{\left|a_{i}-A\right|}{A} \times 100$ 
여기서, R는 상대오차, $\mathrm{a}_{\mathrm{i}}$ 는 샘플빈도별 오염부하량, 그리고 $\mathrm{A}$ 는 실측된 오염부하량을 나타낸다.

\section{3. 결과 및 고찰}

\section{가. 학술림 소하천 유역의 유량특성}

학술림 S지점의 2005년 6월부터 9월까지의 월별 강수량과 실측 월유출량을 산정하였다. 또한 불연속 적으로 측정된 유출량의 오차를 모의하기 위하여 월 별 5 분 단위로 실측된 유량중 최대 및 최소값을 이용 하여 월별 최대 및 최소 유출량을 산정하였으며 Table 1 과 같다. 2005년도의 연강우량은 $1,797 \mathrm{~mm}$ 로 우 리나라의 연평균강우량인 $1,284 \mathrm{~mm}$ 보다 $513 \mathrm{~mm}$ 나 많은 강우량을 보였다. 이중 6 9월 홍수기에만 $1,423 \mathrm{~mm}$ 의 강우가 집중적으로 발생하였다. 본 연구 에서 연속적으로 측정된 6 9월의 총유출량은 26,405,924 $\mathrm{m}^{3}$ 이 발생하였다. 월별 최대유출량은 $486.5 \mathrm{~mm}$ 의 강 우가 발생한 8월에 $8,855,430 \mathrm{~m}^{3}$ 이 발생하였으며, 전체적으로 학술림 소하천의 유출량은 강우량에 비 례하는 것으로 나타났다. 7 월과 9월에는 거의 같은 양의 강우가 발생하였으나, 유출량은 7월보다 9월에 많이 발생한 것으로 나타났다. 이는 많은 양의 걍우 가 발생한 8월에는 유역내 토양이 상당히 포화되어 침투량이 낮아졌기 때문에 7 월과 거의 동일한 강우 가 발생하였어도 9월에 더 많은 유출이 발생한 것으 로 판단되었다. 또한, 8 월의 발생한 강우중에서 땅속 으로 침투되는 침투수가 기저유출 혹은 중간유출의 형태로 장기간에 걸쳐 하천으로 유입되었기 때문으로 판단되었다. 실제로 8 월 한달 동안 약 16 일 정도 연 속적으로 강우가 발생하였다.

6 9월까지는 강우발생일이 많기 때문에 실측수위 자료의 상당히 많은 부분이 연속해서 5 분 단위로 측 정되어 매우 정밀하게 유출량을 산정할 수 있었다. 다 른 많은 연구에서 불연속으로 유출량을 산정할 경우 발생할 수 있는 오차를 모의하기 위하여 6월부터 9월 까지 측정된 일유량자료중에서 월별 최대 및 최소 일 유량자료를 각각 추출하였다. 추출된 일유량자료에 월 별일수를 곱하여 6월, 7월, 8월 그리고 9월의 최대 및 최소 월유출량을 각각 산정하였다. 6월부터 9월까지 4 개월 동안 가능한 최대 - 최소 유출량은 $20,924,419$
Table 1 Monthly precipitation and streamflow, and non-continuous streamflow

\begin{tabular}{|c|c|c|c|c|}
\hline DATE & $\begin{array}{c}\text { Precipitation } \\
(\mathrm{mm})\end{array}$ & $\begin{array}{c}\text { Monthly } \\
\text { measured } \\
\text { streamflow } \\
\left(\mathrm{m}^{3}\right) \\
\end{array}$ & $\begin{array}{c}\text { Monthly } \\
\text { available } \\
\text { maximum } \\
\text { streamflow }\left(\mathrm{m}^{3}\right)\end{array}$ & $\begin{array}{c}\text { Monthly } \\
\text { available } \\
\text { minimum } \\
\text { streamflow }\left(\mathrm{m}^{3}\right)\end{array}$ \\
\hline Jun. 2005 & 240.0 & $4,295,473$ & $9,130,440$ & $3,368,670$ \\
\hline Jul. 2005 & 357.0 & $6,021,064$ & $18,372,429$ & $4,835,070$ \\
\hline Aug. 2005 & 486.5 & $8,855,430$ & $16,934,897$ & $6,578,479$ \\
\hline Sep. 2005 & 340.0 & $7,233,957$ & $13,178,130$ & $6,142,200$ \\
\hline Total & $1,423.5$ & $26,405,924$ & $57,615,896$ & $20,924,419$ \\
\hline
\end{tabular}

$57,615,896 \mathrm{~m}^{3}$ 로 나타났다. 실측유량인 $26,405,924$ $\mathrm{m}^{3}$ 에 비교하여 $79 \sim 218 \%$ 이상으로 유량의 변동이 매우 크게 나타났다. 이는 오염부하량 산정에 큰 영 향을 미치는 유량측정이 불연속적(무강우시 및 강우 시: 각각 4 10회 미만)으로 측정될 경우 산정된 오 염부하량이 실제 오염부하량에 비해 최소 $79 \%$ 에서 최대 $218 \%$ 까지 크게 측정될 가능성이 있음을 의미 한다. 최소유량에서 보다 최대유량에서 오차가 크게 나는 이유는 평시의 유출량보다 강우시 유출량이 급 격히 증가하는 반면 유출지속시간은 매우 짧기 때문 이다. 오염부하량의 측정은 유출량 측정시기에도 매 우 민감한 것으로 나타났다. 따라서 비점원오염부하 산정을 위한 모니터링 연구의 유량은 자동수위계 혹 은 유량계 설치를 통한 연속적인 측정이나 수동측정 인 경우 유량측정오차를 최소화하기 위한 노력이 필 요할 것으로 판단된다. 특히, 현재의 오염총량관리제 도 하에서 안전율은 $10 \%$ 를 인정하고 있다. 이는 오 염부하 산정의 불확실성을 보완하기 위한 최대한의 오염부하 오차를 반영하기 위함이다. 따라서 유량측 정의 불확실성으로 인한 오차가 클 경우 오염총량관 리제도의 안전율 $10 \%$ 는 너무 작게 책정되었거나 혹 은 큰 의미가 없음을 의미할 수 있다.

\section{나. 학술림 소하천 유역의 수질특성}

6 9월의 T-N, NO3-N 및 T-P의 농도는 0.900 $4.900 \mathrm{mg} / \mathrm{L}, 0.039 \sim 1.970 \mathrm{mg} / \mathrm{L}$ 및 $0 \sim 0.720 \mathrm{mg} / \mathrm{L}$ 의 범위를 보였다. 강우시 비점원오염 유출수의 특성 을 가장 잘 반영하는 $\mathrm{T}-\mathrm{N}, \mathrm{NO}_{3}-\mathrm{N}$ 및 $\mathrm{T}-\mathrm{P}$ 의 유량 가중평균농도(Flow-Weighted Mean Concentration: 
Table 2 Selected statistics of measured concentrations of the 58 samples during dry and rainy days 〈Unit: $\mathrm{mg} / \mathrm{L}$ 〉

\begin{tabular}{c|c|c|c|c}
\hline DATE(2005) & Statistics & $\mathrm{T}-\mathrm{N}$ & $\mathrm{NO}_{3}-\mathrm{N}$ & $\mathrm{T}-\mathrm{P}$ \\
\hline \hline \multirow{4}{*}{$\begin{array}{c}\text { June } \\
\sim\end{array}$} & $\mathrm{Max}$ & 4.900 & 1.970 & 0.720 \\
\cline { 2 - 5 } & $\mathrm{Min}$ & 0.900 & 0.039 & 0.000 \\
\cline { 2 - 5 } & Median & 1.900 & 0.900 & 0.080 \\
\cline { 2 - 5 } September & Mean & 2.167 & 0.972 & 0.145 \\
\cline { 2 - 5 } & Standard deviation & 0.856 & 0.372 & 0.177 \\
\cline { 2 - 5 } & FWMC & 2.114 & 0.836 & 0.136 \\
\hline
\end{tabular}

* FWMC: Flow Weighted Mean Concentration

$\mathrm{FWMC})$ 는 각각 $2.114 \mathrm{mg} / \mathrm{L}, 0.836 \mathrm{mg} / \mathrm{L}$ 및 0.136 $\mathrm{mg} / \mathrm{L}$ 로 호소수질기준 I 등급인 T-N(0.200 mg/L 이 하)과 $\mathrm{T}-\mathrm{P}(0.010 \mathrm{mg} / \mathrm{L}$ 이하)와 비교했을 때 각각 10 배 및 13 배 이상 매우 높게 나타났다. 특히, T-N 의 경우에는 공업용수 III등급인 $1.5 \mathrm{mg} / \mathrm{L}$ 에 비해서 도 높은 것으로 나타났다. 이는 많은 강우의 발생시 강우유출수와 함께 지표면에 퇴적되있던 유기물질들 이 하천으로 유입되어 하천수질을 악화시키는 것으 로 판단되었다. 강원대학교 학술림 소하천의 6 9월 강우시에 측정된 수질시료의 최대 - 최소값, 중앙 (Median)값, 산술평균, 표준편차(Standard deviation) 및 유량가중평균농도는 Table 2와 같다.

\section{다. 샘플빈도에 따른 오염부하특성}

연속적으로 측정된 유량자료와 6 9월의 측정된 전 체 58개 수질시료를 이용하여 샘플빈도에 따른 오염 부하특성을 분석하였다. 연구기간동안의 $\mathrm{T}-\mathrm{N}, \mathrm{NO}_{3}-\mathrm{N}$ 및 T-P의 실측 오염부하량은 각각 $126.5 \mathrm{~kg} / \mathrm{ha}, 50.1$ $\mathrm{kg} / \mathrm{ha}$ 및 $8.2 \mathrm{~kg} / \mathrm{ha}$ 로 나타났다(Table 3). 수질샘플 빈도가 오염부하산정에 미치는 영향을 모의하기 위하 여 전체 58 개의 수질시료 중에서 무작위로 수질시료 가 4회, 8회, 12회, 16회, 20회, 24회, 28회, 32회, 36회, 40회, 44회, 48회 및 52회 일때의 오염부하 를 각각 산정하였다. 이와 같은 과정을 100 회 반복 하여 각각의 샘플빈도별 평균 오염부하량을 산정하 였으며 실측값(전체 58개의 수질시료로 산정된 오염 부하량)에 대한 상대오차를 산정하였다(Table 4). 또 한 각각의 샘플빈도별로 100 회 반복하여 산정된 오 염부하량의 최대 및 최소값의 상대오차 범위를 산정
하여 빈도별로 오염부하 산정시 발생할 수 있는 오 차범위를 실측값과 비교·분석 하였다. $\mathrm{T}-\mathrm{N}$ 의 오염부 하는 샘플빈도가 4 20회까지는 상대오차가 약 3 $11 \%$ 정도의 변동을 보였으나, 이후 샘플빈도가 24회 이상일 때에는 상대오차가 $10 \%$ 미만으로 실측값(58 회)에 근접하는 것으로 나타났다. $\mathrm{NO}_{3}-\mathrm{N}$ 의 경우 샘 플빈도가 48회 전까지는 상대오차가 $17 \sim 27 \%$ 이상 높게 발생하였으며, 52 회 이후부터 $10 \%$ 이하로 발 생하였다. T-P의 오염부하 역시 48회 미만에서는 상 대오차가 12 33\% 정도로 나타났으며 52회 이상의 샘플빈도에서 상대오차가 $10 \%$ 미만으로 나타났다.

샘플빈도별로 100 회 반복되어 산정된 오염부하량 중에서 최대 및 최소값을 실측값과 비교한 결과 상대 오차 범위는 샘플빈도가 적을수록 매우 큰 차이를 보 이는 것으로 나타났다. 샘플빈도별 오염부하량의 최대 및 최소값의 상대오차 범위는 $\mathrm{T}-\mathrm{N}, \mathrm{NO}_{3}-\mathrm{N}$ 및 $\mathrm{T}-\mathrm{P}$ 의 샘플빈도가 4 개 일때 $60 \sim 171 \%, 32 \sim 176 \%$ 및 $24 \sim 185 \%$ 로 실측값(100\%)에 비해 최소 $24 \sim 60 \%$ 의 범위로 나타났으며, 최대 1.7 배 이상 높은 것으로 나타났다. 샘플빈도가 증가할수록 수질항목별 상대오 차 범위는 점차 감소하는 경향을 보였다. 이는 샘플 빈도가 낮을수록 수질시료의 대표성에 대한 신뢰도 역시 낮아지기 때문에 유역에서 발생하는 오염부하를 정확하게 산정할 수 없기 때문이다. 최대 및 최소 오 염부하량의 상대오차 범위는 샘플빈도가 증가할수록 상대오차범위는 감소하였으나, 샘플빈도별 평균 오염 부하량의 상대오차는 16 24개 일 때까지 증가하다 가 이후 감소하는 것으로 나타났다. 이는 평균 오염 부하량의 경우에는 샘플빈도별 100회 무작위 측정된 오염부하량의 평균값이기 때문에 샘플갯수가 4 12 개 일때의 오염부하량이 $16 \sim 24$ 개 일때의 오염부하 량과 비교하여 발생하는 상대오차범위는 크지만 오히 려 평균 오염부하량의 상대오차는 적게 산정된 것으 로 판단되었다. Yaksich and Verhoff(1983)와 RomanMas et al.(1994)의 보고에 따르면 강우사상별 12 20 개 혹은 20 개 이상의 수질시료를 채취하고 분석 하여야 $5 \%$ 미만의 오차로 오염부하를 측정할 수 있 다고 하였다. 한국적인 연구상황에서 강우사상당 10 개 이상의 수질시료를 채취하고 분석하기는 매우 어 
렵다. 그러나 오염총량관리제도에서 안전율은 $10 \%$ 를 반영하는데 반하여 오염부하의 측정오차가 $10 \%$ 를 초 과하게 되면 그 연구자료는 정책자료로서 효용성을 잃게 된다. 이제부터는 측정오차가 매우 큰 개략적인 오염부하의 산정을 위한 연구를 지양하고 정밀한 오 염부하를 산정할 수 있는 연구를 수행할 필요가 있 다. 정밀한 오염부하 연구에 기초하여 강우사상별 최 소 수질시료채취 및 분석 빈도를 규정할 필요가 있다. 토지이용, 토질, 강우강도 및 지속시간뿐만 아니라 강 우유출지속시간 등이 상이한 외국의 샘플채취빈도(강 우사상당 12 20회 혹은 20회 이상)를 우리 하천에 적용하는데 있어서 문제가 많을 수 있기 때문이다. 유량과 수질의 정확한 측정을 통한 신뢰성 있는 비 점오염부하의 산정은 오염총량관리제도를 효과적으로 수행하는데 가장 필수적이며 기본적인 자료이다. 그러

Table 3 Loading characteristics of forest watershed from June to September

\begin{tabular}{c|c|c|c}
\hline \multirow{2}{*}{$\begin{array}{c}\text { DATE } \\
(2005)\end{array}$} & $\mathrm{T}-\mathrm{N}$ & $\mathrm{NO}_{3}-\mathrm{N}$ & $\mathrm{T}-\mathrm{P}$ \\
\cline { 2 - 4 } & 1.04 & 0.41 & 0.07 \\
\hline $\begin{array}{c}\text { Jun. } \sim \text { Sep. } \\
\text { (kg/ha/day) }\end{array}$ & 126.5 & 50.1 & 8.2 \\
\hline $\begin{array}{c}\text { Total loads } \\
\text { (kg/ha) }\end{array}$ & \multicolumn{2}{|c}{ Rainy days } \\
\hline
\end{tabular}

나 우리나라는 아직도 각 유역별, 토지이용별 특성이 상이한 대표유역에 대한 정확한 오염부하자료를 확보 하지 못하고 있다. 신뢰성 있는 비점오염부하의 산정 을 위한 수량과 수질의 측정에 본 연구결과는 중요 한 참고 자료로 활용될 수 있을 것이다.

\section{4. 결 론}

본 연구에서는 북한강 중류 산림유역 소하천의 오 염농도특성 및 샘플빈도에 따른 오염부하특성을 분 석하였다.

학술림 소하천의 2005년도 6 9월의 연속적으로 측정된 총유출량은 $26,405,924 \mathrm{~m}^{3}$ 이 발생하였다. 불 연속적으로 추출된 일유량자료를 이용하여 월유출량 을 산정한 결과 20,924,419 57,615,896 $\mathrm{m}^{3}$ 으로 실 측유량에 비해 $79 \sim 218 \%$ 이상의 매우 높은 유량변 동을 보였다. 따라서, 불연속적으로 측정된 $4 \sim 10$ 회 미만의 유량자료를 이용하여 오염부하를 산정할 경우 실제 오염부하량에 비해 최소 $79 \%$ 에서 최대 $218 \%$ 까지 크게 측정될 가능성이 높기 때문에 유량측정은 자동유량계(수위계 혹은 유속계)를 사용하여 연속적으 로 측정해야할 필요가 있는 것으로 판단되었다.

청정한 산림유역의 $\mathrm{T}-\mathrm{N}, \mathrm{NO}_{3}-\mathrm{N}$ 및 $\mathrm{T}-\mathrm{P}$ 의 유량

Table 4 Pollutant loads and relative errors with water quality sampling frequencies

\begin{tabular}{c|c|c|c|c|c|c|c|c|c|c}
\hline \multirow{2}{*}{$\begin{array}{c}\text { Sampling } \\
\text { frequencies }\end{array}$} & \multirow{2}{*}{$\%$} & \multicolumn{2}{|c|}{ Average pollutant loads(kg/ha) } & \multicolumn{2}{|c|}{ Average relative error(\%) } & \multicolumn{3}{|c}{ Max. and Min. of relative error(\%) } \\
\cline { 3 - 11 } & & $\mathrm{T}-\mathrm{N}$ & $\mathrm{NO}_{3}-\mathrm{N}$ & $\mathrm{T}-\mathrm{P}$ & $\mathrm{T}-\mathrm{N}$ & $\mathrm{NO}_{3}-\mathrm{N}$ & $\mathrm{T}-\mathrm{P}$ & $\mathrm{T}-\mathrm{N}$ & $\mathrm{NO}_{3}-\mathrm{N}$ & $\mathrm{T}-\mathrm{P}$ \\
\hline \hline 4 & 6.9 & 130.6 & 58.5 & 6.0 & 3 & 17 & 27 & $60 \sim 171$ & $32 \sim 176$ & $24 \sim 185$ \\
\hline 8 & 13.8 & 135.1 & 61.2 & 6.1 & 7 & 22 & 26 & $79 \sim 146$ & $74 \sim 154$ & $34 \sim 165$ \\
\hline 12 & 20.7 & 135.3 & 62.1 & 6.1 & 7 & 24 & 26 & $82 \sim 138$ & $80 \sim 170$ & $37 \sim 222$ \\
\hline 16 & 27.6 & 137.3 & 63.3 & 5.7 & 10 & 26 & 30 & $85 \sim 133$ & $102 \sim 165$ & $41 \sim 185$ \\
\hline 20 & 34.5 & 137.3 & 63.4 & 5.6 & 11 & 27 & 32 & $91 \sim 134$ & $100 \sim 151$ & $45 \sim 165$ \\
\hline 24 & 41.4 & 136.0 & 63.1 & 5.5 & 8 & 26 & 33 & $91 \sim 130$ & $103 \sim 144$ & $48 \sim 147$ \\
\hline 28 & 48.3 & 135.8 & 63.0 & 5.5 & 7 & 26 & 33 & $90 \sim 130$ & $103 \sim 150$ & $47 \sim 145$ \\
\hline 32 & 55.2 & 135.3 & 62.5 & 5.8 & 7 & 25 & 29 & $95 \sim 119$ & $102 \sim 144$ & $51 \sim 118$ \\
\hline 36 & 62.1 & 134.6 & 61.8 & 6.1 & 6 & 23 & 26 & $97 \sim 119$ & $104 \sim 145$ & $50 \sim 128$ \\
\hline 40 & 69.0 & 133.9 & 61.4 & 6.8 & 6 & 23 & 17 & $100 \sim 118$ & $111 \sim 145$ & $62 \sim 128$ \\
\hline 44 & 75.9 & 132.5 & 60.8 & 7.0 & 5 & 21 & 15 & $101 \sim 113$ & $107 \sim 131$ & $78 \sim 109$ \\
\hline 48 & 84.5 & 122.9 & 56.8 & 9.2 & 3 & 13 & 12 & $96 \sim 104$ & $104 \sim 119$ & $107 \sim 125$ \\
\hline 52 & 89.7 & 124.1 & 57.0 & 9.0 & 2 & 8 & 6 & $96 \sim 103$ & $102 \sim 119$ & $100 \sim 112$ \\
\hline 58 & 100.0 & 126.5 & 50.1 & 8.2 & 0 & 0 & 0 & 100 & 100 & 100 \\
\hline
\end{tabular}


가중평균농도(FWMC)는 $2.114 \mathrm{mg} / \mathrm{L}, 0.836 \mathrm{mg} / \mathrm{L}$ 및 $0.136 \mathrm{mg} / \mathrm{L}$ 로 나타나 T-N(0.200 mg/L 이하)과 T-P $(0.010 \mathrm{mg} / \mathrm{L}$ 이하) 호소수질기준 I 등급과 비교했을 때 매우 높게 나타났다. 이는 지표면의 유기물질들이 강우시 강우유출수와 함께 하천으로 유입되어 하천 수질을 악화시키는 것으로 판단되었다.

본 연구에서 $\mathrm{T}-\mathrm{N}$ 을 제외한 $\mathrm{NO}_{3}-\mathrm{N}$ 과 $\mathrm{T}-\mathrm{P}$ 의 비 점오염원부하를 상대오차 $10 \%$ 이하로 산정하기 위해 서는 희망 샘플 숫자의 $89.7 \%$ 이상 분석하여야 성취 가능한 것으로 나타났다. 따라서 외국의 문헌에서 제 기된 $5 \%$ 이내의 신뢰성 있는 비점오염부하를 산정하 기 위해 강우사상당 최소 12 회의 수질샘플이 필요할 경우 본 연구에서 사용된 수질샘플(58개)의 오염부하 의 오차를 $10 \%$ 이내로 산정하기위해서는 강우사상당 최소 10 개 이상의 수질샘플의 채취 및 분석이 필요 한 것으로 판단되었다. 그러나 외국의 자료를 우리나 라에 적용하기는 어렵기 때문에 우리나라 소하천에 적 합한 정밀한 오염부하를 산정하기 위한 샘플채취 및 분석 빈도를 설정하기 위한 연구가 수행되어야 할 것 으로 판단되었다.

본 연구는 2005년도 한강수계관리위원회(한강유 역환경청)에서 시행한 환경기초조사사업 연구결과 의 일부로 연구지원에 감사한다.

이 논문은 2007년도 2단계 두뇌한국(BK)21 사 업에 의하여 지원되었음.

\section{References}

1. 신용철, 최중대, 임경재, 심혁호, 류창원, 양재의, 유경열, 북한강 중류 산간농업 소하천에서의 오 염부하특성분석, 한국농공학회논문집, $47(6), \mathrm{pp}$. 83-92(2005).

2. 최중대, 농촌유역의 관리가 비점원 오염물질의 하천유입에 미치는 영향, 농촌개발연구, $1, \mathrm{pp}$. 91-107(1997).
3. 최중대, 이찬만, 최예환, 토지이용이 농업소유역의 수질에 미치는 영향, 한국수자원학회논문집, 32(4), pp. 501-510(1999).

4. 환경부, 수질오염공정시험법(1996).

5. 환경부(2005), 비점오염원관리 업무 편람.

6. 환강수계관리위원회, 비점오염원의 오염부하 유출 량 조사-(2005).

7. Clement, A., and Buzas, K., Use of ambient water quality data to refine emission estimates in the Danube basin, Water Science Tech, 40(10), pp. 35-42.

8. Miller, P. S., Engel, R. H., Mohtar, R. H., and Mitchell, J. K., Statistical assessment of historical water quality data and mass load time evolution, ASAE Paper No. 012247. St. Joseph, Mich.: ASAE(2001).

9. Richards, R. P., and Roerish, E. D., Monte carlo studies of sampling strategies for estimationg tributary loads, Water Resources Research, 23(10), pp. 1939-1948(1987).

10. Robertson, D. M., and Roerish, E. D., Influence of various water quality sampling strategies on load estimates for small streams, Water Resources Research, 35(12), pp. 37473759(1999).

11. Roman-Mas. A., Stogner, R. W., Doyle, U. H., and Klaine, S. J., Assessment of agricultural non-point source pollution and best management practices for the Beaver Creek watershed, West Tennessee. In G. L. Pederson, ed. Proceedings, American Water Resources Association National Symposium on Water Quality, Nashville, TN, April 17-20, 1994. American Water Resources Association, Bethesda, MD.

12. Yaksich, S. M., and Verhoff, F. H., Sampling strategy for river pollutant transport. J. Environ. Eng. 109, pp. 219-231(1983). 